\title{
Silicate Covering Layer on Pyrite Surface in the Presence of Silicon-Catechol Complex for Acid Mine Drainage Prevention
}

\author{
Mutia Dewi Yuniati ${ }^{1,3}$, Tsuyoshi Hirajima ${ }^{1,2, *}$, Hajime Miki ${ }^{1}$ and Keiko Sasaki ${ }^{1}$ \\ ${ }^{1}$ Department of Earth Resources Engineering, Kyushu University, Fukuoka 819-0395, Japan \\ ${ }^{2}$ Research and Education Center of Carbon Resources, Kyushu University, Fukuoka 816-8580, Japan \\ ${ }^{3}$ Research Center for Geotechnology, Indonesian Institute of Sciences, Bandung 40135, Indonesia
}

In this paper, prevention of pyrite oxidation by carrier microencapsulation (CME) was investigated. A possible layer structure was suggested following analysis with electrochemical and surface analysis techniques. Electrochemical study of treated pyrite samples showed that treatment with silicon-catechol (Si-Cat) for $6 \mathrm{~h}$ at an initial $\mathrm{pH}$ of 9.5 gave the best barrier properties and suppression of the samples. Scanning electron microscopy with energy-dispersive X-ray, and Fourier transform infrared (FTIR) analyses confirmed the presence of a silicate layer on the surface of treated pyrite. X-ray photoelectron spectroscopy indicated that the coating layers on the treated pyrite samples consisted of a network of Fe-O-Si and Si-O-Si units bonded to the surface of pyrite. The Si-O-C asymmetric stretching mode was also observed in FTIR spectra. Detailed spectroscopic analyses confirmed the formation of a silicate polymer on a silica-quinone layer, which resulted in the effective suppression effect shown by Si-Cat-treated pyrite at increasing pH. [doi:10.2320/matertrans.M-M2015821]

(Received May 25, 2015; Accepted July 8, 2015; Published August 28, 2015)

Keywords: pyrite oxidation suppression, silicon-catechol complex, polymerization, silica-quinone layer

\section{Introduction}

Acid mine drainage (AMD) is produced when sulfidebearing material is exposed to oxygen and water. The production of AMD usually, but not exclusively, occurs during mining of iron sulfide mineral (pyrite), which is the most abundant metal sulfide in nature. Although this process occurs naturally, mining and processing of metal ores can promote AMD generation simply through increasing the quantity of sulfides exposed to oxygen and water. ${ }^{1)}$ Naturally occurring bacteria can accelerate AMD production by microbial oxidation of ferrous ions to ferric ones at low $\mathrm{pH}^{2,3)}$

A promising approach to prevent AMD is passivation, in which a thin organic or inorganic protective coating is formed on the surface of pyrite to prevent its contact with the atmosphere, water, and bacteria that promote oxidation. Numerous passivation agents have been investigated. ${ }^{4,5)} \mathrm{A}$ method known as carrier microencapsulation (CME) that uses aqueous solutions of metal ions $\left(\mathrm{Si}^{4+}\right.$ or $\left.\mathrm{Ti}^{4+}\right)$ complexed with an organic carrier such as catechol (Cat), i.e., $\mathrm{Si}[\mathrm{Cat}]_{3}{ }^{2-}$ or $\mathrm{Ti}[\mathrm{Cat}]_{3}{ }^{2-}$, proposed by Satur et al. ${ }^{6)}$ and Jha et al. ${ }^{7,8)}$ has become a promising method for the practical suppression of pyrite oxidation. ${ }^{6-8}$ In this method, complexed $\mathrm{Si}[\mathrm{Cat}]_{3}{ }^{2-}$ or Ti[Cat $]_{3}{ }^{2-}$ is decomposed selectively on the surface of pyrite to form a silicon or titanium oxide and/ or hydroxide coating that protects against oxidation. There are many reports of the formation of silicate polymers when silica or its derivatives are used as coating agents. ${ }^{9-13)}$ However, the characteristics of the covering layers generated from Si-Cat complexes are poorly understood. Therefore, we decided to investigate the polymerization of the covering layer of pyrite. Another drawback of this method is the high cost of Cat.

As the utilization of low rank coal in Indonesia increases, it has been proposed to use hydrothermal treatment to upgrade

*Corresponding author, E-mail: hirajima@mine.kyushu-u.ac.jp low rank coal. ${ }^{14)}$ It is known that the waste aqueous solution from hydrothermal treatment of low rank coal contains Cat. Utilizing this waste solution for CME of pyrite can reduce both the waste from hydrothermal treatment of low rank coal and the chemical cost of CME.

We previously reported suppression of pyrite oxidation using a Si-Cat complex formed using waste solution from hydrothermal treatment of low rank coal as the Cat source. ${ }^{14-16)}$ Our results indicated that a silica-quinone coating was formed and the oxidation rate of pyrite could be suppressed by pretreatment with Si-Cat. However, a more systematic investigation of the silica-quinone coating is needed to clarify the mechanisms involved in the formation of this coating. To address this issue, the morphological characteristics and chemical composition of the silicaquinone coating formed using Si-Cat were evaluated by scanning electron microscopy with energy-dispersive X-ray spectroscopy (SEM-EDX), Fourier transform infrared (FTIR) spectroscopy, and X-ray photoelectron spectroscopy (XPS). The ability of the silica-quinone coating to suppress oxidation of pyrite is also investigated by static potential measurements and electrochemical impedance spectroscopy (EIS).

\section{Experimental Material and Methods}

\subsection{Material}

Crystalline pyrite from Victoria mine, Navajún, La Rioja, Spain, was used as experimental material. The X-ray diffraction study of this material was carried out using XRD (Rigaku Ultima IV diffractometer, Tokyo, Japan) and the result is shown in Fig. 1. It can be seen that the sample was identical to pure pyrite.

For morphological analyses (FTIR, SEM-EDX, and XPS), a pyrite sample was ground to $-38 \mu \mathrm{m}$ in diameter on an agate mortar in a nitrogen-purged glove. After grinding, the washing method of Sasaki et al. ${ }^{17)}$ was adapted to remove the surface oxide. The sample was washed with ethanol in a beaker by an ultrasonic bath for 30 seconds. After removing 


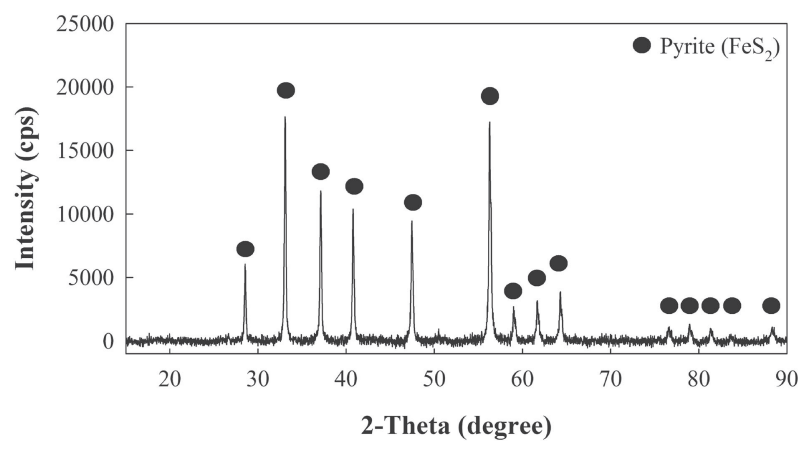

Fig. 1 XRD patterns of pyrite sample.

the supernatant, the pyrite was washed with $1 \mathrm{~mol} / \mathrm{L}$ nitric acid solution for one minute, distilled water (two times) and acetone (four times). Finally, the washed pyrite was dried by freeze dehydration.

For electrochemical analysis, a working electrode was prepared from a pyrite sample by cutting it into cubes with working surfaces of approximately $1.10 \mathrm{~cm}^{2}$ exposed to the electrolyte. One side of the pyrite electrode was used as the electrode surface and the other side was connected to a copper wire using silver conductive paste and cemented with epoxy resin. The electrode surface was polished with \#400 to \#4000 emery paper, a Texmet (Buehler, Illinois, USA) perforated non-woven pad, and a DP-Nap (Struers, Ballerup, Denmark) fine polishing cloth mounted on a plate using $3 \mu \mathrm{m}$ and $1 \mu \mathrm{m}$ diamond sprays. After polishing, the electrode was rinsed with ethanol and distilled water to remove polishing residues

\subsection{Experimental}

\subsubsection{Preparation of coating solution}

$7.00 \mathrm{mmol} / \mathrm{L}$ Catechol $\left(\mathrm{C}_{6} \mathrm{H}_{4}[\mathrm{OH}]_{2}\right)$ (Wako, special grade) solution was prepared using ultrapure water. Subsequently, $2.34 \mathrm{mmol} / \mathrm{L}$ sodium metasilicate nonahydrate $\left(\mathrm{Na}_{2} \mathrm{SiO}_{3}\right.$. $9 \mathrm{H}_{2} \mathrm{O}$ ) (Wako, special grade) was added to the catechol solution. Solution $\mathrm{pH}$ was adjusted to the desired value using $\mathrm{HCl}$ and $\mathrm{KOH}$, and used for pyrite surface treatment. This solution referred as silicon-catechol (Si-Cat) complex.

The concentration ratio of silicate solution to catechol was $1: 3$ because it is known that $1 \mathrm{~mol}$ of silicon forms a complex with $3 \mathrm{~mol}$ of catechol. ${ }^{8)}$ We used waste solution from hydrothermal treatment of low rank coal ${ }^{14)}$ with a catechol concentration of $7.00 \mathrm{mmol} / \mathrm{L}$ as the source of catechol in this work. Jha et $a{ }^{8}{ }^{8}$ reported that the passivation effect of catechol on pyrite oxidation by CME is similar for Si-Cat concentrations of $1-10 \mathrm{mmol} / \mathrm{L}$.

\subsubsection{Electrochemical analysis}

The pyrite working electrode was immersed in the coating solution (see section 2.2.1.), stirred with a magnetic stirrer at $100 \mathrm{rpm}$. After a predetermined stirring time (1, 6, and $12 \mathrm{~h}$ ), the working electrode was air dried for $30 \mathrm{~min}$, and used for electrochemical measurements in $0.10 \mathrm{~mol} / \mathrm{L}$ sulfuric acid.

The electrochemical measurements were performed using three standard electrode cells consisting of a working electrode, a platinum counter electrode, and an $\mathrm{Ag} / \mathrm{AgCl}$ reference electrode. The three electrode cells and electrolyte $(0.10 \mathrm{~mol} / \mathrm{L}$ sulfuric acid $)$ were placed in a glass container.
Static potential and electrochemical impedance spectroscopy (EIS) experiments of untreated and treated pyrite samples were performed at room temperature using an electrochemical instrument (Solartron Analytical 1280 C, Hampshire, UK).

Static potential experiments were carried out at $800 \mathrm{mV}$ for $300 \mathrm{~s}$ and all the measured potentials were reported with respect to the standard hydrogen electrode. The EIS measurements were performed at open circuit potential in the frequency range of $0.1-20,000 \mathrm{~Hz}$ with peak-to-peak amplitude of $10 \mathrm{mV}$. The impedance data was modelled to an equivalent circuit (EC) using the data analysis program Zview $^{\circledR}$ (Scribner Associates, Inc., North Carolina, USA), using iterative empirical data fitting combined with trial circuit elements chosen based on theoretical considerations.

2.2.3 Pretreatment of pyrite and morphological analysis

In a $250 \mathrm{~mL}$ bottle, $10.00 \mathrm{~g}$ of washed pyrite sample was added to $100 \mathrm{~mL}$ of Si-Cat solution. After predetermined stirring time $(1,6$, and $12 \mathrm{~h})$ at $100 \mathrm{rpm}$ and $25^{\circ} \mathrm{C}$, the solid residues from each treatment bottle were recovered by filtration and dried by freeze dehydration. Dry solid residue referred as Si-Cat treated pyrite samples.

SEM-EDX analyses were performed using (Keyence VE9800, Osaka, Japan) and FTIR investigations were performed using FT-IR-670 Plus (JASCO, Tokyo, Japan [accumulation, 100 times; resolution, $4 \mathrm{~cm}^{-1}$; detector, triglycine sulfate; wave numbers, $\left.400-4000 \mathrm{~cm}^{-1}\right]$ ).

XPS analyses were carried out using XPS ESCA 5800F (New York, USA) with $\mathrm{Al} \mathrm{K} \alpha$ X-ray source $(1486.6 \mathrm{eV})$ operated at $200 \mathrm{~W}$. The samples were cleaved under vacuum in the sample preparation chamber prior to delivery, without breaking vacuum, to the XPS analysis chamber. The vacuum in the sample preparation chamber is approximately $10^{-8}$ Torr when the sample is cleaved and the pressure in the analysis chamber is $10^{-9}$ Torr during the XPS measurements. The samples were first examined in wide scan $(80 \mathrm{~W}$ of the analyzer pass energy) to identify all the elements present, the various elemental regions were scanned $(40 \mathrm{~W}$ of the analyzer pass energy) in order to extract information on chemical bonding and oxidation stages. The collected data were analyzed with Casa XPS software (Ver. 2.3.16). Background corrections were made using the Shirley method for the Fe 2 p, S 2 p, O 1s, and Si $2 p$ spectra. ${ }^{18)}$ Peak shapes were defined using a Gaussian-Lorentzian function. Binding energy (EB) calibration was based on $\mathrm{C} 1 \mathrm{~s}$ at $E_{\mathrm{B}}[\mathrm{C} 1 \mathrm{~s}]=$ $284.6 \mathrm{eV}$.

\section{Results and Discussion}

In our previous work (Kitagawa et al. ${ }^{14)}$ ) we investigated the direct leaching behavior of CME-treated pyrite and untreated pyrite for 30 days. Pyrite oxidation was suppressed by more than $50 \%$ following CME. In this study, oxidation effects over a shorter duration were investigated by electrochemical study to investigate silicate layer formation and the stabilization achieved by CME.

\subsection{Effect of treatment time of silicate coating on pyrite oxidation suppression}

Figure 2 shows static potential experiments data that 


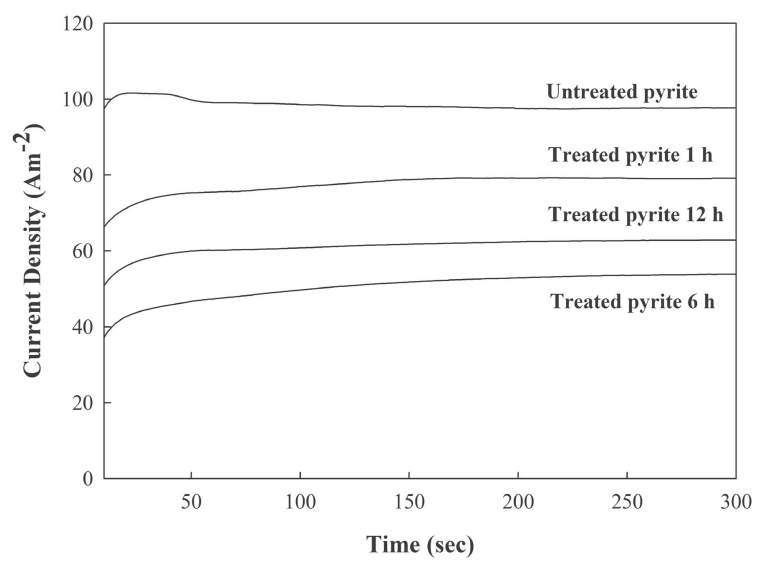

Fig. 2 Potentiostatic curves of untreated and Si-Cat treated pyrite samples initially $\mathrm{pH} 9.5$ with different treatment time in $0.1 \mathrm{M} \mathrm{H}_{2} \mathrm{SO}_{4}$.

completed to measure the oxidation rate of pyrite with and without pretreatment. Pretreatment were conducted initially at $\mathrm{pH} 9.5$ (natural $\mathrm{pH}$ of Si-Cat) for 1,6 , and $12 \mathrm{~h}$. These experiments were measured at $800 \mathrm{mV}$ for $300 \mathrm{~s}$. The average results of two times measurements are shown as curves of current density with time. Current density is the anodic current of the working electrode in the working area of $1.10 \mathrm{~cm}^{2}$.

From these results, the anodic currents of Si-Cat treated pyrite samples $(1,6$, and $12 \mathrm{~h}$ ) are lower than that of the untreated pyrite. Because the anodic current represents the oxidation rate, the lower anodic currents of Si-Cat treated pyrite samples mean that the oxidation rates of these samples are lower than that of the untreated pyrite. Figure 2 shows that pyrite sample treated for $6 \mathrm{~h}$ has the lowest oxidation rate and largest suppression effect. This result is consistent with the study conducted by Bessho et al. ${ }^{12)}$ that showed equilibrium $\mathrm{pHs}$ of silica solutions were reached after $6 \mathrm{~h}$ of stirring. Pyrite sample treated for $1 \mathrm{~h}$ shows the lowest suppression effect. It may be due to the shorter time that used to complete the coating process. Meanwhile, longer treatment time $(12 \mathrm{~h})$ also shows lower suppression effect than $6 \mathrm{~h}$ treatment. This might be caused by the formation of metalcatechol complex, where catechol can form stable complexes with various di- and trivalent metal ions such as iron. ${ }^{19)}$ Basic solutions of catechol react with iron(III) to give the red (catecholato)iron(III) complexes $\left[\mathrm{Fe}\left(\mathrm{C}_{6} \mathrm{H}_{4} \mathrm{O}_{2}\right)_{3}\right]^{3-}$, and finally change to a black color on exposure to the air. ${ }^{20)}$ It can be seen that the solution after $12 \mathrm{~h}$ treatment turned darker than other treatment times. This reaction caused the Si-Cat complex not to work completely during the coating process.

\subsection{Effect of $\mathrm{pH}$ of silicate coating on pyrite oxidation suppression}

A series of experiments (EIS, SEM-EDX, FTIR, and XPS) was conducted to evaluate the effect of initial $\mathrm{pH}$ of Si-Cat complex on pyrite oxidation suppression. EIS is often used to obtain information on the properties of systems, such as the presence of defects, reactivities of interfaces, adhesion, and barrier properties. In this work, EIS was used to study the barrier properties of pyrite surface in the presence of a silicaquinone layer.
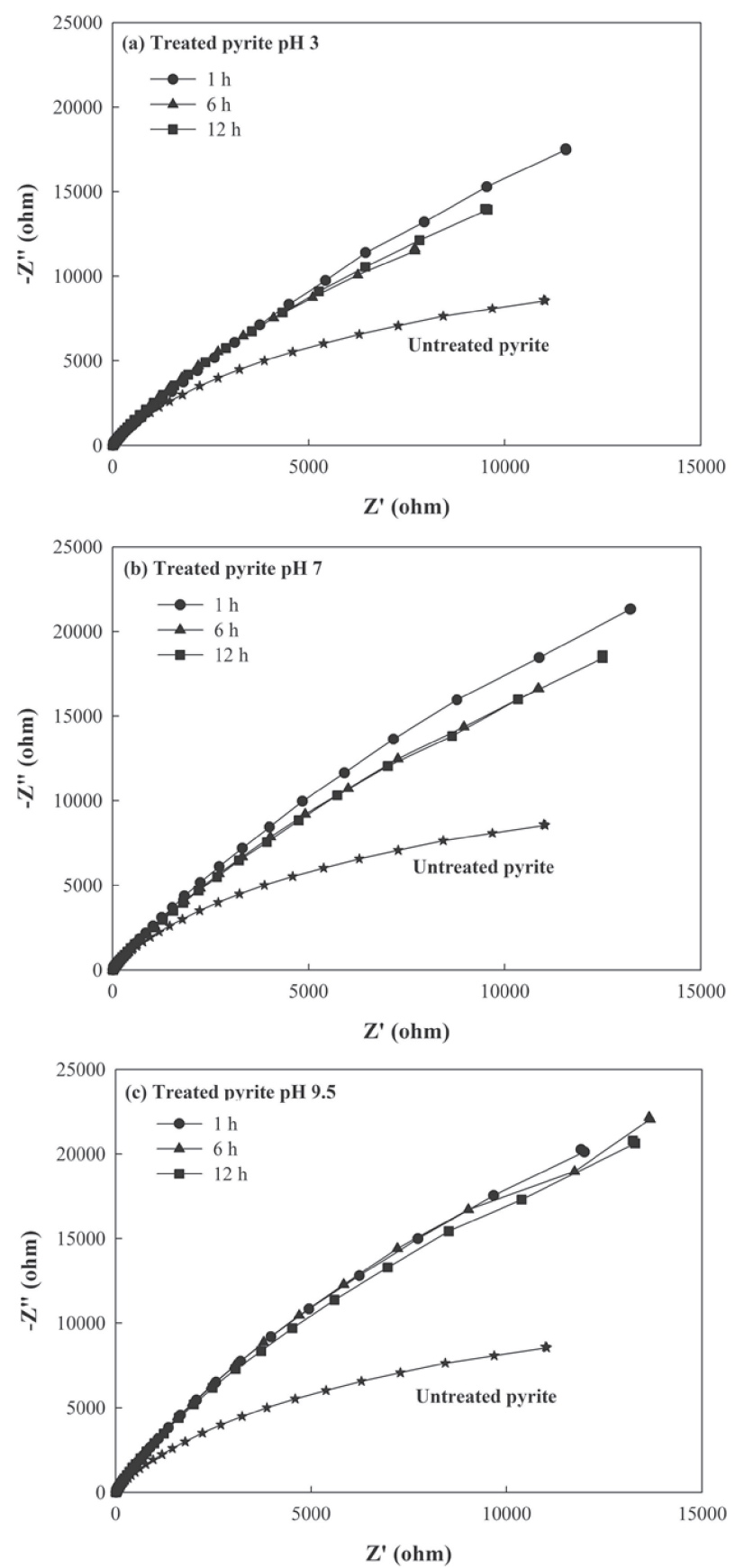

Fig. 3 EI spectra of Si-Cat treated pyrite samples initially $\mathrm{pH}$ (a) 3, (b) 7, (c) 9.5 ; compared with untreated pyrite.

Like resistance, impedance is a measure of the ability of a circuit to resist the flow of electrical current. Electrochemical impedance is usually measured by applying an alternating current (AC) potential to an electrochemical cell and then measuring the current through the cell. The technique is based on the measurement of current through an electrode when a sinusoidal potential is applied. The impedance is therefore expressed in terms of magnitude, $Z_{0}$ (ratio of voltage to current) and a phase shift, $\phi$; composed of a real part, $Z^{\prime}$, and an imaginary part, $Z^{\prime \prime}$. A Nyquist plot is obtained by plotting the real part on the $x$-axis and the imaginary part on the $y$-axis of a chart.

The EIS complex plane plots (Nyquist plots) of pyrite samples are shown in Fig. 3. The Nyquist plot for the 
(a)

$Z_{1} \quad$ (b)

(b) $\quad \mathrm{Z}_{1}$

$\mathrm{Z}_{2}$

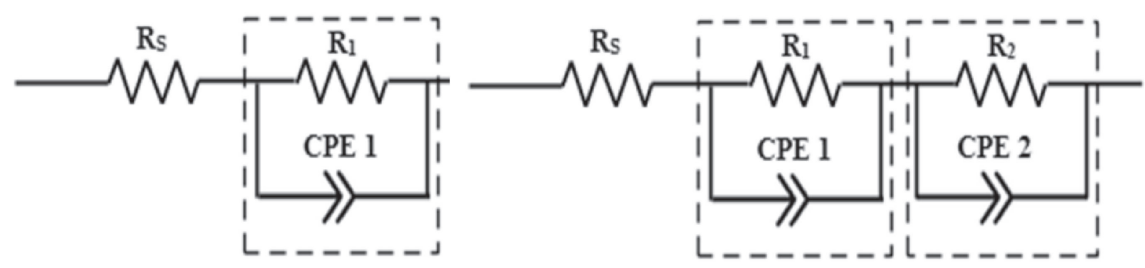

Fig. 4 EC models of pyrite samples.

untreated pyrite is a semicircle, and that of treated pyrite has a larger radius than that of untreated pyrite. The $Z^{\prime}$ value at the starting point of each semicircle indicates solution resistance, and a semicircle shape indicates the impedance of electrode, including both electrode resistance and capacitance. ${ }^{21)}$ The radius of the semicircle represents the resistance of the electrode. The flat semicircle shape indicates that the electrode surface is rough and contains defects, so for this fitting we used a constant phase element (CPE) instead of a capacitor. Using an alternating current frequency $\omega$, imaginary unit $j$, and parameters $T$ and $P$, the complex impedance of a constant phase element, $Z_{\mathrm{CPE}}$, is defined by following equation.

$$
Z_{\mathrm{CPE}}=\frac{1}{T(j \omega)^{P}}
$$

When the exponential parameter $P$ is equal to 1 , the impedance of a $\mathrm{CPE}, Z_{\mathrm{CPE}}$, becomes equal to the impedance of a capacitance by substituting $C$ for $T$ in the above equation.

Figure 4 presents a fitting for the circuit calculated from the Nyquist plot in Fig. 3. Figure 4(a) shows the fitting circuit for untreated pyrite, which consists of solution resistance $\left(R_{\mathrm{S}}\right)$ and a parallel of constant phase element (CPE1) and resistance $\left(R_{1}\right)$ that represents an untreated pyrite electrode circuit $\left(Z_{1}\right.$ part). For treated pyrite, the semicircle diameter is drastically increased compared with that of untreated pyrite (see Fig. 3). This result can be fitted as two parallel circuits in series (Fig. 4(b)). This indicates that in addition to the pyrite circuit, another coating layer exists as the $Z_{2}$ component, which consists of resistance $\left(R_{2}\right)$ and capacitance (CPE2). ${ }^{22)}$

This calculated circuit allowed the parameters of the EC elements for pyrite samples to be calculated; the values are listed in Table 1.

It is obvious that $R_{2}$ values of $\mathrm{Si}$-Cat treated pyrite samples are higher than that of untreated pyrite. These results show the coating layer is created on the surface of treated pyrite samples. From the listed $R_{2}$ values, $6 \mathrm{~h}$ Si-Cat treated pyrite initially $\mathrm{pH} 9.5$ has larger $R_{2}$ value and better barrier properties than other treatment conditions which confirm the results of the static potential measurements (effect of treatment time). At $\mathrm{pH}$ lower than 9 the formation of Si-Cat complexes might be incomplete and simple hydrolysis may predominate. ${ }^{23,24)}$ Based on those reports, silicate covering layer was not created completely and the suppression effect was lower than that of Si-Cat treated pyrite initially $\mathrm{pH} 9.5$. These data also supported by Ultraviolet-visible (UV) absorption spectra studies conducted by Sever and Wilker ${ }^{25}$ ) that showed that at low $\mathrm{pH}(<7)$, catechol is reduced
Table 1 EC element parameters obtained by fitting experimental impedance data for untreated and Si-Cat treated pyrite samples with EC model shown in Fig. 4.

\begin{tabular}{ccrrc}
\hline Pyrite & Treatment time, $\mathrm{h}$ & $R_{\mathrm{S}}, \mathrm{ohm}$ & $R_{1}, \mathrm{ohm}$ & $R_{2}, \mathrm{ohm}$ \\
\hline Untreated & - & 9.46 & 1078 & - \\
\hline \multirow{2}{*}{ Treated pH 3 } & 1 & 8.88 & 793.6 & 65323 \\
& 6 & 9.94 & 242.1 & 39621 \\
& 12 & 9.70 & 1217.0 & 45160 \\
\hline \multirow{2}{*}{ Treated pH 7 } & 1 & 9.64 & 992.5 & 69842 \\
& 6 & 9.77 & 1545.0 & 69521 \\
& 12 & 10.73 & 1726.0 & 58489 \\
\hline & 1 & 10.29 & 678.3 & 58652 \\
Treated pH 9.5 & 6 & 11.55 & 1188.0 & 75192 \\
& 12 & 10.16 & 1855.0 & 69344 \\
\hline
\end{tabular}

and coordination complexes are dissolved instead of cross linked.

Figure 5 show SEM-EDX images of $6 \mathrm{~h}$ Si-Cat treated

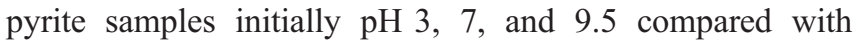
untreated pyrite.

All figures show that silica is present on pyrite surface of untreated and three treated pyrite samples, but the silica densities of the treated pyrite samples are much higher than that of the untreated sample. Si contents of the untreated

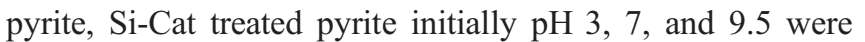
$0.34 \%, 0.71 \%, 1.56 \%$ and $2.59 \%$, respectively. These results confirm that silica adsorption occurred, and silicate coatings were formed on the surfaces of the treated pyrite samples.

The high silica density of treated pyrite initially $\mathrm{pH} 7$ and 9.5 was probably caused by the formation of a silica polymer. ${ }^{26,27)}$ At $\mathrm{pH}>4$, the ferric hydroxide precipitated on the pyrite surface reacts with Si-containing species to form a ferric hydroxide-silica barrier.

Attenuated total reflectance Fourier transfer infrared spectroscopy (ATR-FTIR) has been used to study the adsorption of Si-Cat complex onto pyrite surface (Fig. 6). The presence of quinone was confirmed from the previous study. ${ }^{16)}$ In the present study, we investigated the presence of polymerization (via Si-O-Si lingkages). Peaks observed at $955-960 \mathrm{~cm}^{-1}$ are present in the treated pyrite samples. These absorption peaks correspond to $\mathrm{Fe}-\mathrm{O}$ stretching of the $\mathrm{Fe}-\mathrm{O}-\mathrm{Si}$ bond. ${ }^{28)}$ The occurrence of $\mathrm{Fe}-\mathrm{O}-\mathrm{Si}$ bonds indicates that $\mathrm{Si}-\mathrm{OH}$ groups (silanol) reacted with $\mathrm{FeOOH}$ on the surface of pyrite. $\mathrm{FeOOH}$ is produced on the surface of pyrite from released ferric ion as follows.

$$
\mathrm{Fe}^{3+}+2 \mathrm{H}_{2} \mathrm{O}=\mathrm{FeOOH}+3 \mathrm{H}^{+}
$$


(a)
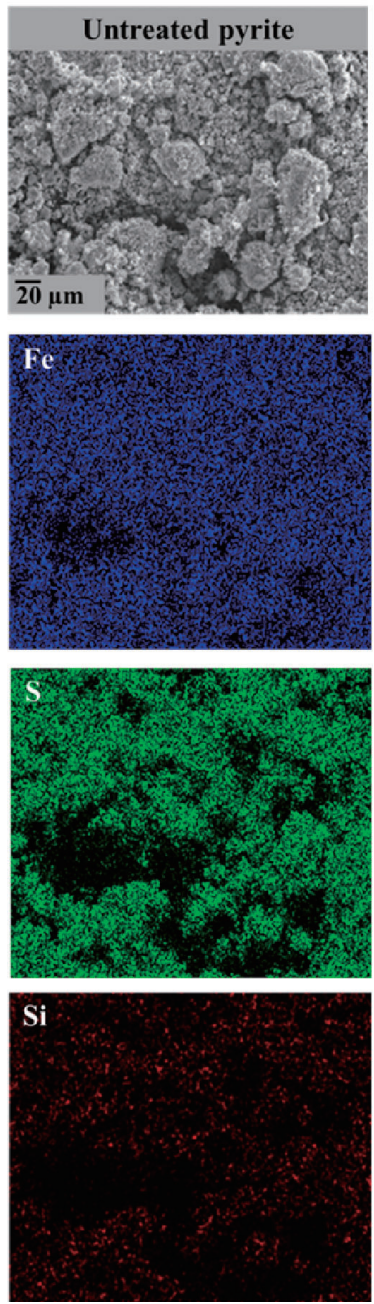

(b)
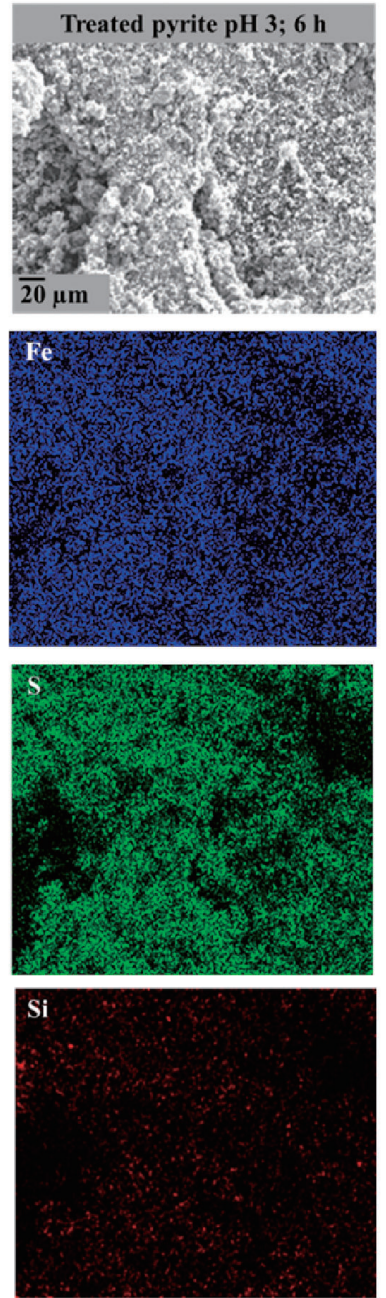

(c)

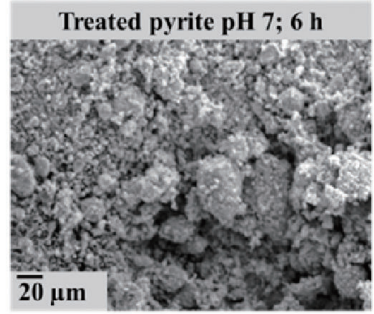

Fe
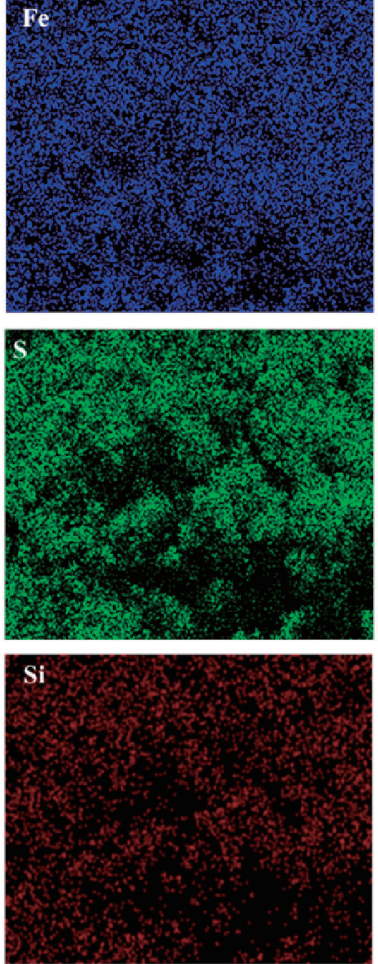

(d)
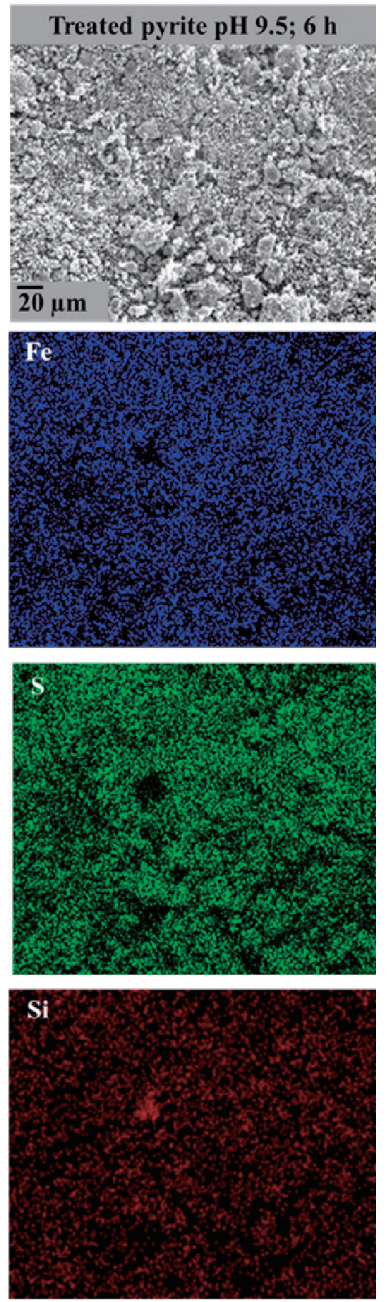

Fig. 5 SEM-EDX element mapping of (a) untreated pyrite; $6 \mathrm{hr}$ Si-Cat treated pyrite initially pH (b) 3, (c) 7, (d) 9.5 .

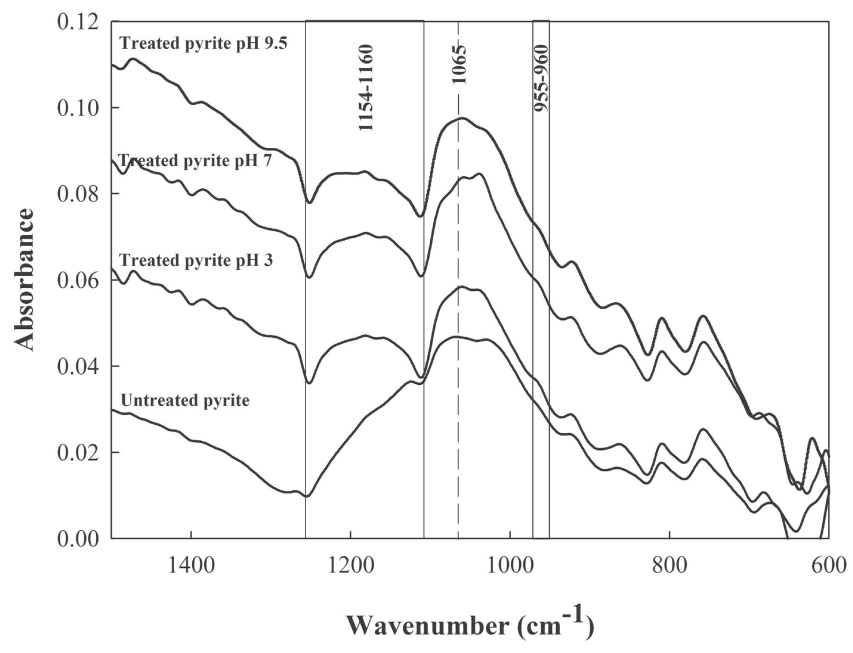

Fig. 6 FTIR spectra of untreated and $6 \mathrm{~h}$ Si-Cat treated pyrite samples.

The bonding mode near $1065 \mathrm{~cm}^{-1}$ is for the $\mathrm{Si}-\mathrm{O}-\mathrm{C}$ asymmetric streching mode in a ring link. ${ }^{29,30)}$ This bond shows that the aromatic ring attach to $\mathrm{Si}-\mathrm{O}$ bonds. Besides, significant peaks are observed at $1154-1160 \mathrm{~cm}^{-1}$. According to Carlson and Schwertmann, ${ }^{31)}$ the peaks observed at 1154
$1160 \mathrm{~cm}^{-1}$ were assigned to a shift of Si-O-Si in polymerized $\mathrm{Si}$. As the Si-O-Si (siloxanes) chains become longer or branched, the Si-O-Si absorption becomes broader and more complex. As surface coverage increases with the $\mathrm{pH}$, the presence of polymerized species becomes evident and the peak intensity due to adsorbed silicate shows the highest absorbance for Si-Cat treated pyrite initially $\mathrm{pH} 9.5$.

To confirm the surface product, XPS analysis of pyrite samples have been conducted before and after $6 \mathrm{~h}$ Si-Cat treatment initially at $\mathrm{pH} 3,7$, and 9.5. The narrow scanned and corresponding decomposed of Fe $2 p, S$, and $\mathrm{O} 1 \mathrm{~s}$ spectra are shown in Fig. 7.

XP-spectra of Fe 2p, S 2p, O 1s, and Si 2p for untreated pyrite and treated pyrite samples were analyzed by peak separation and the results are summarized in Table 2.

The Fe $2 p$ spectra of the four samples are presented in Fig. 7(a). This Fe $2 p$ figure indicates that Si-Cat treatment decreased iron in pyrite peaks at $707.6 \mathrm{eV}^{32)}$ and covered the treated pyrite surfaces with silicate coating as the peaks at around $711.3 \mathrm{eV}$ attributable to iron/silicon oxide ${ }^{33)}$ were observed. As the $\mathrm{pH}$ increased, the peak area associated with iron/silicon dioxide increases in the Fe $2 \mathrm{p}_{3 / 2}$ spectra (Table 2). The shared peaks confirm the formation of Fe-O-Si bonds in the treated pyrite samples, which are consistent with 


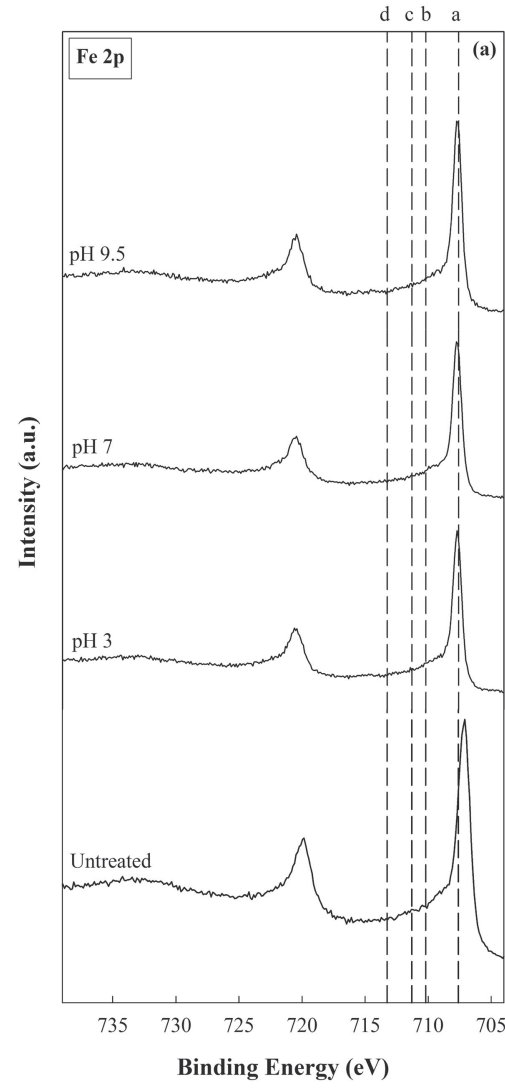

a: $707.6 \mathrm{eV}$ pyrite $^{32)}$ b: $710.2 \mathrm{eV}$ iron oxyhydroxide ${ }^{34)}$ c: $711.3 \mathrm{eV}$ iron/silicon dioxide ${ }^{33)}$ d: $713.25 \mathrm{eV} \mathrm{Fe}_{2}\left(\mathrm{SO}_{4}\right)_{3}{ }^{38)}$

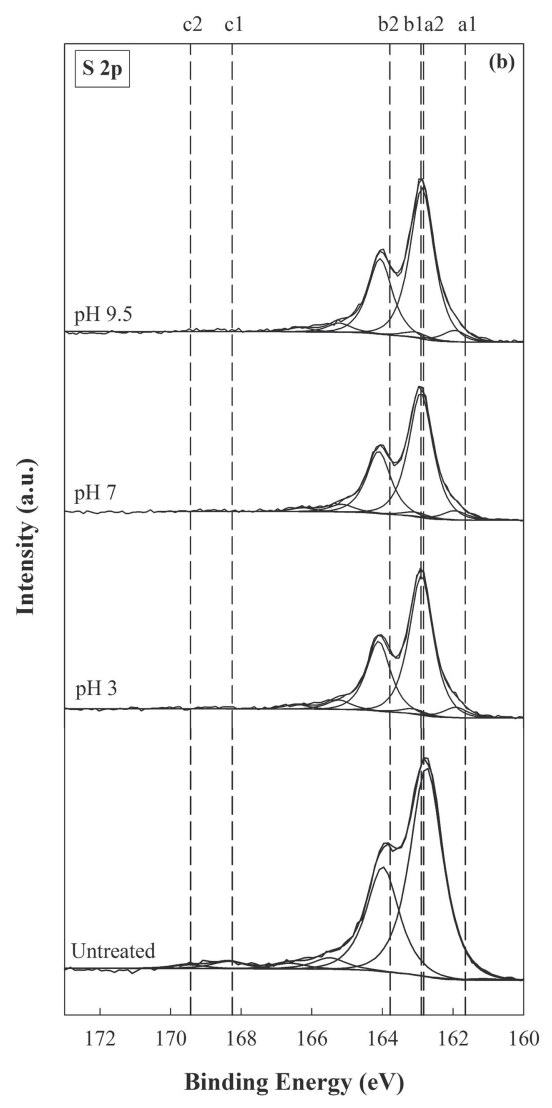

a1: $2 \mathrm{p}_{3 / 2} 161.65 \mathrm{eV}, \mathrm{a} 2: 2 \mathrm{p}_{1 / 2} 162.83 \mathrm{eV} \mathrm{S}^{2-}{ }^{37)}$ b1: $2 \mathrm{p}_{3 / 2} 162.9 \mathrm{eV}, \mathrm{b} 2: 2 \mathrm{p}_{1 / 2} 163.78 \mathrm{eV} \mathrm{S}_{2}{ }^{2-}$ c1: $2 \mathrm{p}_{3 / 2} 168.25 \mathrm{eV}, \mathrm{c} 2: 2 \mathrm{p}_{1 / 2} 169.43 \mathrm{eV} \mathrm{SO}_{4}{ }^{2-}{ }^{37)}$

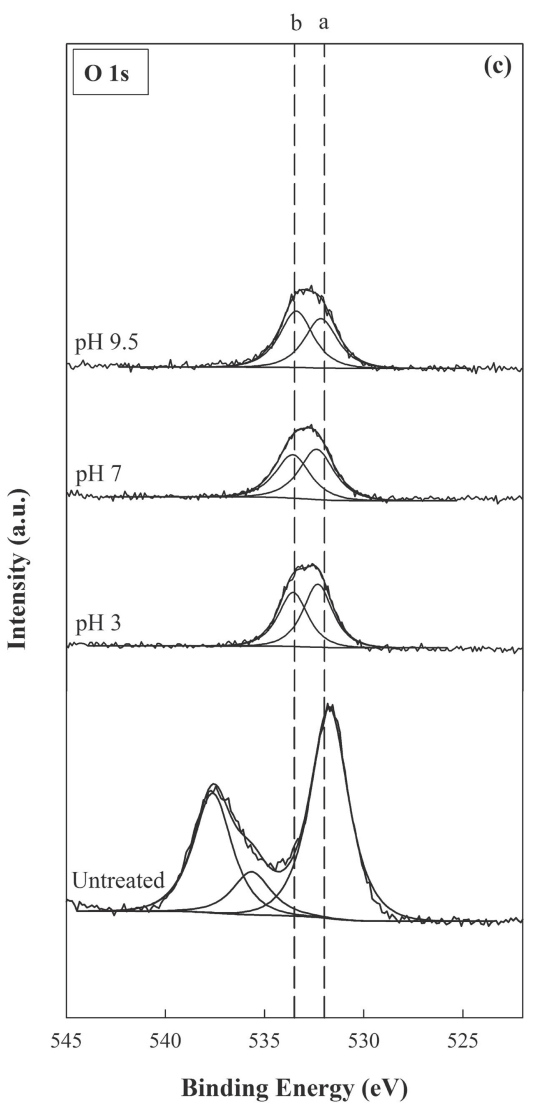

a: $532.0 \mathrm{eV} \mathrm{Fe}\left(\mathrm{SO}_{4}\right)_{3}{ }^{36)}$

b: $533.5 \mathrm{eV}$ iron/silicon dioxide

Fig. 7 XP spectra of untreated and $6 \mathrm{~h} \mathrm{Si-Cat} \mathrm{treated} \mathrm{pyrite} \mathrm{samples} \mathrm{with} \mathrm{(a)} \mathrm{Fe} \mathrm{2p} \mathrm{peaks,} \mathrm{(b)} \mathrm{S} \mathrm{2p} \mathrm{peaks,} \mathrm{and} \mathrm{(c)} \mathrm{O} \mathrm{1s} \mathrm{peaks.}$

Table 2 Comprehensive atomic allocation based on the measurement of narrow scan of $\mathrm{Fe}, \mathrm{S}, \mathrm{O}$, and Si spectra of untreated and $6 \mathrm{~h}$ Si-Cat treated pyrite samples.

\begin{tabular}{|c|c|c|c|c|c|c|c|c|c|c|c|c|c|c|c|}
\hline \multirow{2}{*}{ Pyrite } & & \multicolumn{2}{|c|}{$\mathrm{Fe} 2 p_{3 / 2} \mathrm{Fe} 2 p_{3 / 2}$} & \multicolumn{2}{|c|}{$\mathrm{Fe} 2 \mathrm{p}_{3 / 2} \mathrm{Fe} 2 \mathrm{p}_{3 / 2}$} & \multirow{2}{*}{$\begin{array}{l}\mathrm{S} 2 \mathrm{p}_{3 / 2} \\
\mathrm{a} 1\end{array}$} & \multirow{2}{*}{$\begin{array}{l}\mathrm{S} 2 \mathrm{p}_{1 / 2} \\
\mathrm{a} 2\end{array}$} & \multirow{2}{*}{$\begin{array}{l}\mathrm{S} 2 \mathrm{p}_{3 / 2} \\
\mathrm{~b} 1\end{array}$} & \multirow{2}{*}{$\begin{array}{l}\mathrm{S} 2 \mathrm{p}_{1 / 2} \\
\mathrm{~b} 2\end{array}$} & \multirow{2}{*}{$\begin{array}{l}\mathrm{S} 2 \mathrm{p}_{3 / 2} \\
\mathrm{c} 1\end{array}$} & \multirow{2}{*}{$\begin{array}{l}\mathrm{S} 2 \mathrm{p}_{1 / 2} \\
\mathrm{c} 2\end{array}$} & \multirow{2}{*}{$\begin{array}{l}\mathrm{O} 1 \mathrm{~s} \\
\mathrm{a}\end{array}$} & \multirow{2}{*}{$\begin{array}{l}\mathrm{O} 1 \mathrm{~s} \\
\mathrm{~b}\end{array}$} & \multirow{2}{*}{$\begin{array}{l}\text { Si } 2 p \\
\mathrm{SiO}_{2} \\
\end{array}$} & \multirow{2}{*}{$\begin{array}{l}\text { Si } 2 p \\
\text { Si-O-Si }\end{array}$} \\
\hline & & $\mathrm{a}$ & $\mathrm{b}$ & $\mathrm{c}$ & $\mathrm{d}$ & & & & & & & & & & \\
\hline \multirow[t]{2}{*}{ Untreated } & $E_{\mathrm{B}} / \mathrm{eV}$ & 707.2 & 710.0 & - & 713.8 & 161.1 & 162.2 & 162.8 & 164.0 & 168.4 & 169.5 & 531.7 & - & 102.5 & - \\
\hline & AREA & 6966.2 & 529.4 & & 146.8 & 37.1 & 18.5 & 5276.9 & 2638.4 & 185.8 & 92.9 & 5399.0 & & 75.8 & \\
\hline \multirow[t]{2}{*}{ Treated $\mathrm{pH} 3$} & $E_{\mathrm{B}} / \mathrm{eV}$ & 707.7 & 710.0 & 711.1 & - & 161.9 & 163.1 & 162.9 & 164.1 & - & - & 532.3 & 533.6 & - & 103.5 \\
\hline & AREA & 3625.7 & 366.9 & 207.0 & & 194.0 & 97.0 & 2585.7 & 1292.9 & & & 1244.6 & 1071.2 & & 110.8 \\
\hline \multirow[t]{2}{*}{ Treated $\mathrm{pH} 7$} & $E_{\mathrm{B}} / \mathrm{eV}$ & 707.7 & 710.0 & 711.2 & - & 162.0 & 163.1 & 162.9 & 164.1 & - & - & 532.4 & 533.6 & - & 103.7 \\
\hline & AREA & 3514.5 & 384.2 & 248.7 & & 174.8 & 87.4 & 2350.2 & 1175.1 & & & 1162.8 & 1005.0 & & 117.3 \\
\hline \multirow[t]{2}{*}{ Treated $\mathrm{pH} 9.5$} & $E_{\mathrm{B}} / \mathrm{eV}$ & 707.7 & 710.0 & 711.2 & & 161.9 & 163.0 & 162.9 & 164.1 & - & - & 532.2 & 533.4 & - & 103.8 \\
\hline & AREA & 4230.4 & 442.8 & 291.3 & & 215.4 & 107.7 & 2827.3 & 1413.7 & & & 1099.9 & 1258.3 & & 130.8 \\
\hline Average & $E_{\mathrm{B}} / \mathrm{eV}$ & 707.6 & 710.0 & 711.1 & 713.8 & 161.7 & 162.9 & 162.9 & 164.1 & 168.4 & 169.5 & 532.2 & 533.5 & 102.5 & 103.7 \\
\hline STDEV & & 0.28 & 0.03 & 0.01 & - & 0.42 & 0.42 & 0.07 & 0.05 & - & - & 0.30 & 0.10 & - & 0.13 \\
\hline
\end{tabular}

analysis of the FTIR spectra (Fig. 6). The peak observed at $710.0 \pm 0.03 \mathrm{eV}$ correspond to iron oxyhydroxide. ${ }^{34)}$

The presented S 2p spectra consist of two major doublets representing bulk mono sulfide and disulfide. ${ }^{35)} \mathrm{S} 2 \mathrm{p}$ data (Fig. 7(b) and Table 2) are fitted with two S 2p doublets based on prior research on pyrite, which is the peaks at $162.9 \mathrm{eV}$ and 163.78 were assigned to the disulfide group ${ }^{36)}$ and the peaks at $161.65 \mathrm{eV}$ and $162.83 \mathrm{eV}$ feature to a monosulfide group. ${ }^{37)}$ For $\mathrm{S} 2 \mathrm{p}$ peaks, sulfate peaks at 168.25 and $169.43 \mathrm{eV}^{37)}$ can be seen on the untreated pyrite which we believed were produced during exposure of the sample to air because untreated pyrite sample was not covered by coating layer. This result also supported by iron(III) sulfate peak at $713.25 \mathrm{eV}^{38}$ ) that can be seen only on untreated pyrite. Natural oxidation of untreated pyrite might cause the following oxidation reaction to produce iron sulfate.

$$
2 \mathrm{FeS}_{2}+7 \mathrm{O}_{2}+2 \mathrm{H}_{2} \mathrm{O}=\mathrm{Fe}_{2}\left(\mathrm{SO}_{4}\right)_{3}+4 \mathrm{H}^{+}+\mathrm{SO}_{4}{ }^{2-}
$$


In the $\mathrm{O} 1 \mathrm{~s}$ region (Fig. 7(c)), there are two main components at $E_{\mathrm{B}}[\mathrm{O} 1 \mathrm{~s}]=532.2 \pm 0.30 \mathrm{eV}, 533.5 \pm 0.1 \mathrm{eV}$ assigning to sulfate, and iron/silicon dioxide, respectively. As shown from the figure, it is clear that relative intensities of sulfate decreased around $78 \%$ by Si-Cat treatment at all $\mathrm{pH}$ values tested. From these results, it might be caused by the silica-quinone layers that cover the surface of treated pyrite samples and inhibit pyrite oxidation. The peaks observed at around $533.5 \mathrm{eV}$ only present in the Si-Cat treated pyrite samples and it is possibly from iron/silicone dioxide peaks. Other two peaks which give rise to high energy peak observed at $E_{\mathrm{B}}[\mathrm{O} 1 \mathrm{~s}]=535.6$ and $537.6 \mathrm{eV}$ on untreated pyrite sample are not completely clear. The most rational explanation is that these oxygen species correspond to molecular oxygen occluded in intergrain of the metal oxide interface layer. ${ }^{39)}$

Variation of the Si $2 p$ XPS binding energies among the various samples is considered to correlate with the $\mathrm{Si}-\mathrm{O}$ bonds. The energy difference between the $\mathrm{Si} 2 \mathrm{p}_{3 / 2}$ and Si $2 p_{1 / 2}$ levels is $\sim 0.5 \mathrm{eV}$ causing the two peaks to overlap. ${ }^{40)}$ The Si $2 p$ spectra of pyrite samples are illustrated in Fig. 8. The peaks observed at $103 \mathrm{eV}$ and $103.8 \mathrm{eV}$ are attributed to silicon dioxide and siloxanes, respectively. ${ }^{9,41)}$ From the present study, the position of the $\mathrm{Si} 2 \mathrm{p}$ peaks of treated pyrite samples shift from 103.5 to $103.8 \mathrm{eV}$ as the silicate surface concentration increases with $\mathrm{pH}$ and show the formation of polymerization via siloxanes bonding. Also, the Si peak shifted to higher binding energy, which means that the binding energy of Si-O increased after treatment and also increased with $\mathrm{pH}$. This observation supports the results of impedance analysis, which indicated that coating layer resistance increased with increasing $\mathrm{pH}$. These $\mathrm{Si} 2 \mathrm{p}$ peak positions correlate with the Si-O bands in the FTIR spectra in which polymeric silicate species are present via siloxanes bond. In Table 2, the fitted data for silicon dioxide and siloxanes bonds are shown. The siloxanes surface area for SiCat treated pyrite initially $\mathrm{pH} 3$ is lower than those for Si-Cat treated pyrite initially $\mathrm{pH} 7$ and 9.5 clearly indicating a lower degree of silicate polymerization.

Based on the analysis of SEM-EDX, FTIR, and XPS of the treated pyrite samples described above, a tentative mechanism of pyrite oxidation suppression by $\mathrm{Si}$-Cat is proposed. The coating behavior may be explained in terms of the reaction between pyrite and silicate ions, as shown in Fig. 9.

The first step involves hydrolysis of the Si-Cat complex, which yields reactive $\mathrm{Si}-\mathrm{OH}$ groups (silanol) and quinone (eq. (4)). It has been reported that Si-Cat complex was selectively oxidized on the surface of pyrite, and such silanol groups can be present only on the surface of pyrite. ${ }^{15)}$

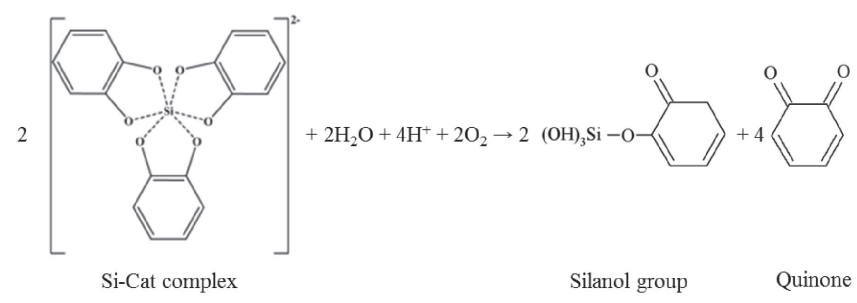

(4)

The next step of the process (Fig. 9(a)) is that the pyrite surface is oxidized by air and water. The resulting $\mathrm{Fe}^{3+}$ is

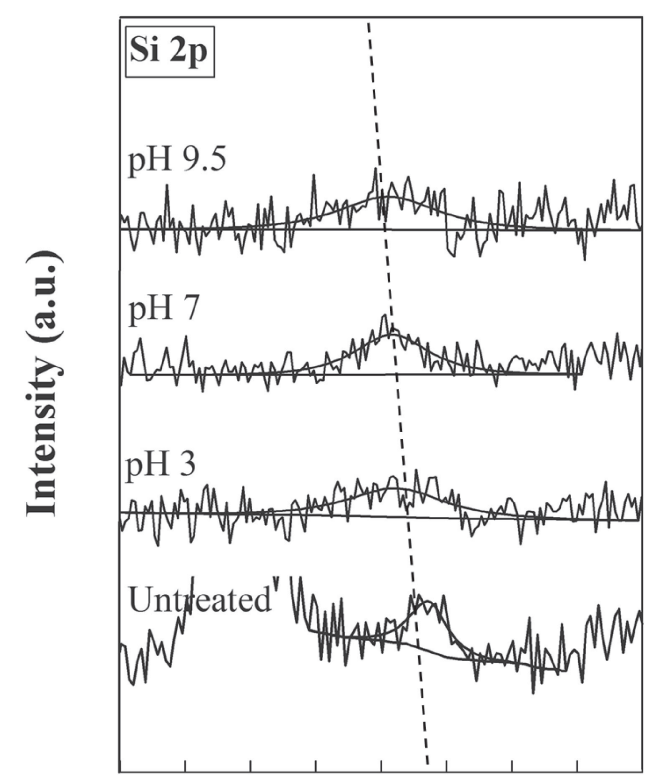

1121101081061041021009896

\section{Binding Energy (eV)}

Fig. $8 \mathrm{XP}$ spectra of untreated and $6 \mathrm{~h} \mathrm{Si-Cat} \mathrm{treated} \mathrm{pyrite} \mathrm{samples} \mathrm{with}$ Si $2 p$ peaks.

hydrolyzed to form iron hydroxide (Fig. 9(b)) on the surface of pyrite. Silanol groups then react with hydroxyl groups on the pyrite surface to form hydrogen bonds, as illustrated in Fig. 9(c). This reaction can occur because silanol groups can exist only on the surface of pyrite. As shown in this figure, suppression of hydrolysis of pyrite is the motivation of CME and lower $\mathrm{pH}$ might reduce this effect. This reaction model can explain the effect of $\mathrm{pH}$ on layer resistance shown in Fig. 3.

In the last step, the hydrogen bonds formed between silanol groups and hydroxyl groups are converted into Fe-O$\mathrm{Si}$ bonds, releasing water. This is consistent with FTIR analysis, where peaks at $955-960 \mathrm{~cm}^{-1}$ were attributed to $\mathrm{Fe}-$ $\mathrm{O}$ stretching of Fe-O-Si bonds (Fig. 6). Also, residual free silanol groups can further condense with each other to form Si-O-Si bonds (Fig. 9(d)), which is consistent with the observed FTIR peaks at $1154-1160 \mathrm{~cm}^{-1}$ assigned to a shift of Si-O-Si in polymerized Si. This step occurs during drying after CME treatment. The drying conditions induce dehydration in this step.

The proposed mechanism shows similar pathway with Diao et al. ${ }^{9}$ ) whereas the formation of covalent bonds (Fe-O$\mathrm{Si}$ and $\mathrm{Si}-\mathrm{O}-\mathrm{Si}$ ) were occur on the pyrite surface by using tetraethylorthosilicate (TEOS) and n-propyltrimethoxysilane (NPS). In Si-Cat treatment, the coating layer much more bulky than TEOS and NPS treatment. It caused by the attachment of 1 quinone molecule on the silanol group (eq. (4)). With this structure, the resulting coating layer probably could give bigger oxidation suppression effect.

\section{Conclusions}

In this study, we systematically examined Si-Cat adsorption and polymerization on the surface of pyrite. Treatment 


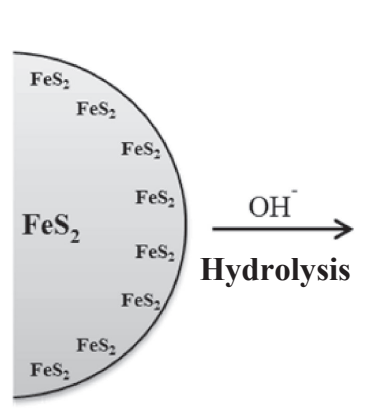

Pyrite

(a)

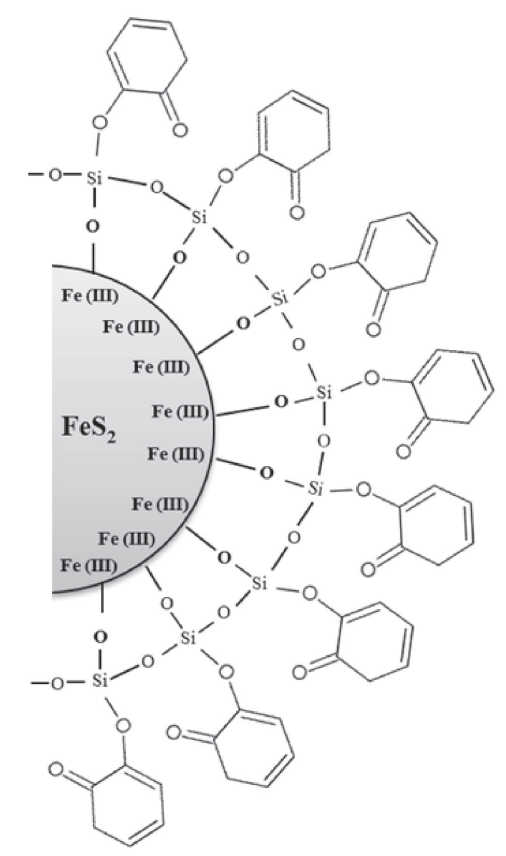

(d)

Silica-quinone coated pyrite

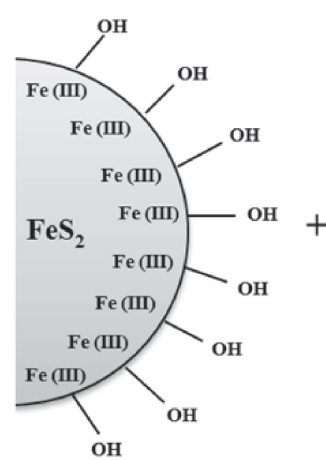

(b)
Dry / Dehydration

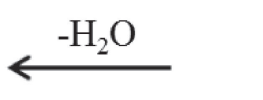

Fig. 9 Proposed mechanism of pyrite oxidation suppression by Si-Cat complex.

of pyrite with Si-Cat under various conditions resulted in differences in the suppression of pyrite oxidation.

Electrochemical measurements demonstrated that treatment with $\mathrm{Si}-\mathrm{Cat}$ for $6 \mathrm{~h}$ at an initial $\mathrm{pH}$ of 9.5 gave the best barrier properties and pyrite oxidation suppression effect of the samples. The coating formed was shown by SEM-EDX to be silica-rich. Evidence provided by FTIR and XPS analyses demonstrated that the coating layer on treated pyrite samples consisted of a network of Fe-O-Si and Si-O-Si units bonded to the surface of pyrite. The Si-O-C asymmetric stretching mode was also observed in FTIR spectra.

Detailed FTIR and XPS data revealed that (i) silicate polymerization occurs on the treated pyrite samples, (ii) SiCat-treated pyrite with an initial $\mathrm{pH}$ of 9.5 showed the highest degree of polymerization based on the intensity and peak area of Si-O-Si bonds. These results confirm that the Si-Cat complex is selectively oxidized on the surface of pyrite to produce silanol groups, followed by hydrolysis with hydroxide on the surface of pyrite, then formation of a protective layer by dehydration during drying. Overall, our results further confirm that it is the formation of silicate polymer on the silica-quinone layer of treated pyrite samples that suppresses pyrite oxidation.

\section{Acknowledgements}

The authors would like to acknowledge the Ministry of Education, Culture, Sports, Science and Technology (MEXT), and JSPS KAKENHI Grant Nos. 24246149 and $15 \mathrm{H} 02333$ for financial and other supports.

\section{REFERENCES}

1) A. Akcil and S. Koldas: J. Clean. Prod. 14 (2006) 1139-1145.

2) R. L. P. Kleinmann, D. A. Crerar and R. R. Pacellli: Min. Eng. Littleton 3 (1981) 300-305.

3) C. A. Backes, I. D. Pulford and H. J. Duncan: Soil Use Manage. 9 (1993) 30-34.

4) S. B. Lalvani, B. A. DeNeve and A. Weston: Fuel 69 (1990) 15671569.

5) S. B. Lalvani, B. A. DeNeve and A. Weston: Corrosion 47 (1991) 5561.

6) J. Satur, N. Hiroyoshi, M. Tsunekawa and H. Okamoto: Int. J. Miner. Process. 83 (2007) 116-124. 
7) R. K. T. Jha, J. Satur, N. Hiroyoshi, M. Ito and M. Tsunekawa: Miner. Eng. 21 (2008) 889-893.

8) R. K. T. Jha, J. Satur, N. Hiroyoshi, M. Ito and M. Tsunekawa: Miner. Process. Extr. M. 33 (2012) 89-98.

9) Z. Diao, T. Shi, S. Wang, X. Huang, T. Zhang, Y. Tang, X. Zhang and R. Qiu: Water Res. 47 (2013) 4391-4402.

10) H. Setyawan, F. Fajaroh, W. Widiyastuti, S. Winardi, I. W. Lenggoro and N. Mufti: J. Nanopart. Res. 14 (2012) 807.

11) P. J. Swedlund, S. Sivaloganathan, G. M. Miskelly and G. I. N. Waterhouse: Chem. Geol. 285 (2011) 62-69.

12) M. Bessho, T. Wajima, T. Ida and T. Nishiyama: Environ. Earth Sci. 64 (2011) 311-318.

13) D. M. Kargbo and S. Chatterjee: J. Environ. Eng. 131 (2005) 13401349.

14) K. Kitagawa, T. Hirajima and K. Sasaki: Proc. Spring Meeting of MMIJ, (MMIJ, 2011) pp. 119-120.

15) M. D. Yuniati, T. Hirajima, H. Miki and K. Sasaki: Proc. Int Symposium on Earth Science and Technology, (CINEST, 2013) pp. 193-196.

16) M. D. Yuniati, T. Hirajima, H. Miki and K. Sasaki: Proc. Int. Symposium on Earth Science and Technology, (CINEST, 2014) pp. $108-111$.

17) K. Sasaki, M. Tsunekawa, T. Ohtsuka and H. Konno: Geochim. Cosmochim. Acta 59 (1995) 3155-3158.

18) D. A. Shirley: Phys. Rev. B 5 (1972) 4709-4714

19) N. Schweigert, A. J. B. Zehnder and R. I. L. Eggen: Environ. Microbiol. 3 (2001) 81-91.

20) B. F. Anderson, D. A. Buckingham, G. B. Robertson, J. Webb, K. S. Murray and P. E. Clark: Nature 262 (1976) 722-724.

21) V. F. Lvovich: Impedance Spectroscopy, Application to Electrochemical and Dielectric Phenomena, (John wiley \& Sons. Hoboken, New Jersey, 2012) pp. 26-34
22) N. Hiroyoshi, S. Kuroiwa, H. Miki, M. Tsunekawa and T. Hirajima: Hydrometallurgy 74 (2004) 103-116.

23) H. Bartels: Helv. Chim. Acta 47 (1964) 1605-1609.

24) C. W. Correns: Clay Miner. Bull. 4 (1961) 249-265.

25) M. J. Sever and J. J. Wilker: Dalton Trans. 7 (2004) 1061-1072.

26) Y. L. Zhang and V. P. Evangelou: Soil Sci. 163 (1998) 53-62.

27) K. Fytas and P. Bousquet: CIM Bulletin 95 (2002) 1063.

28) U. Schwertmann and H. Thalmann: Clays Clay Miner. 11 (1976) 189200.

29) L. J. Bellamy: The Infrared Spectra of Complex Molecules, (Chapman and Hall Ltd., London, 1975) p. 9.

30) L. J. Bellamy: The Infrared Spectra of Complex Molecules, (Chapman and Hall Ltd., London, 1975) p. 92.

31) L. Carlson and U. Schwertmann: Geochim. Cosmochim. Acta 45 (1981) 421-429.

32) H. W. Nesbitt, G. M. Bancroft, A. Pratt and M. Scaini: Am. Mineral. 83 (1998) 1067-1076.

33) M. Gettings and A. J. Kinloch: J. Mater. Sci. 12 (1977) 2511-2518.

34) A. P. Grosvenor, B. A. Kobe, M. C. Biesinger and N. S. McIntyre: Surf. Interface Anal. 36 (2004) 1564-1574.

35) K. Sasaki, K. Takatsugi, K. Ishikura and T. Hirajima: Hydrometallurgy 100 (2010) 144-151.

36) D. Brion: Appl. Surf. Sci. 5 (1980) 133-152.

37) H. W. Nesbitt and I. J. Muir: Geochim. Cosmochim. Acta 58 (1994) 4667-4679.

38) M. Descostes, F. Mercier, N. Thromat, C. Beaucaire and M. GautierSoyer: Appl. Surf. Sci. 165 (2000) 288-302.

39) A. I. Stadnichenko, S. V. Koshcheev and A. I. Boronin: Moscow University Chem. Bull. 62 (Allerton Press, Inc., 2007) pp. 343-349.

40) D. Pleul, R. Frenzel, M. Eschner and F. Simon: Anal. Bioanal. Chem. 375 (2003) 1276-1281.

41) E. Paparazzo: Surf. Interface Anal. 24 (1996) 729-730. 